\title{
Helically coiled segmented flow tubular reactor for the hydroformylation of long-chain olefins in a thermomorphic multiphase system
}

\author{
Michael Jokiel $^{\mathrm{a}}$, Nicolas Maximilian Kaiser ${ }^{\mathrm{b}}$, Péter Kováts ${ }^{\mathrm{b}}$, Michael Mansour ${ }^{\mathrm{b}, \mathrm{c}}$, \\ Katharina Zähringer ${ }^{\mathrm{b}}$, Krishna Deo Prasad Nigam ${ }^{\mathrm{d}}$, Kai Sundmacher ${ }^{\mathrm{a}, \mathrm{b}, *}$ \\ ${ }^{a}$ Max Planck Institute for Dynamics of Complex Technical Systems, Department of Process Systems Engineering, Sandtorstr. 1, D-39106 Magdeburg, Germany \\ ${ }^{\mathrm{b}}$ Otto-von-Guericke-University Magdeburg, Department Process \& Systems Engineering, Universitätsplatz 2, D-39106 Magdeburg, Germany \\ ${ }^{c}$ Mechanical Power Engineering Department, Faculty of Engineering, Mattaria, Helwan University, 11718 Cairo, Egypt \\ ${ }^{\mathrm{d}}$ Indian Institute of Technology - Delhi, New Delhi 110016, India
}

\section{H I G H L I G H T S}

- Excellent mixing and mass transfer properties of the helically coiled reactor.

- Yield and selectivity predictions are in agreement to the experimental results.

- The novel reactor setup increases the yield and selectivity of the target product.

\section{A R T I C L E I N F O}

\section{Keywords:}

Hydroformylation

Homogeneous catalysis

Miniplant

Long chain olefin

Helix reactor

\begin{abstract}
A B S T R A C T
To intensify new or existing chemical processes, novel reactor designs have to be developed. For a homogeneously catalyzed multiphase model reaction, the hydroformylation of 1-dodecene, Kaiser et al. [13] theoretically derived a promising tandem reactor system applying a model-based rector synthesis and dimensioning approach. The reactor tandem, consisting of a helically coiled tubular reactor (HCTR) followed by a continuously stirred tank reactor (CSTR), was constructed and firstly operated within this work. For the validation of the reactor design methodology, a comprehensive hydrodynamic study focusing on the HCTR was performed. Different complementary techniques were used to investigate the geometry influences on mixing and the gasliquid mass transfer, and liquid phase mixing in smaller model geometries. Since the same Reynolds-number and flow regime in the model geometries and the HCTR were ensured, the transfer of the results between these geometries was possible. The outcome confirms, that the geometrical parameter only minor influence the excellent mixing properties of coiled tubes and the helix geometry has enhanced gas-liquid mass transfer rates. In a next step, the HCTR + CSTR-tandem was operated with closed catalyst recycle and optimized reaction parameters. Thereby, full conversion of 1-dodecene and a selectivity of up to 0.70 to the linear aldehyde, tridecanal, were achieved. These values match the predictions of the numerical calculations and are higher than published results for this process. The outcomes of this study confirm the assumptions made by Kaiser et al. [13] during the reactor dimensioning and validate the reactor network design approach.
\end{abstract}

\section{Introduction}

In the near future the availability of crude oil is going to decrease and consequently new sources of raw material are required for the production of chemicals. Therefore, a lot of effort is made to exploit new resources. Naturally, many unsaturated fatty acids are available, which are suitable for the production of chemicals [3]. However, we have to be very careful not to exploit too much of this feedstock for this. The double bonds of the unsaturated acids can, for example, be used for carboxylation, oligomerization or metathesis to synthesize fine chemicals [1]. The hydroforymlation reaction is the most important one in the group of carboxylation reactions, as around 10 million tons of aldehydes are synthesized annually [4]. The name hydroformylation stands for the addition of synthesis gas $\left(\mathrm{CO}, \mathrm{H}_{2}\right)$ on the alkene bond in

\footnotetext{
* Corresponding author at: Max Planck Institute for Dynamics of Complex Technical Systems, Department of Process Systems Engineering, Sandtorstr. 1, D-39106 Magdeburg, Germany.

E-mail address: sundmacher@mpi-magdeburg.mpg.de (K. Sundmacher).
} 


\begin{tabular}{|c|c|}
\hline \multicolumn{2}{|c|}{ Nomenclature } \\
\hline \multicolumn{2}{|c|}{ Abbreviations } \\
\hline BiPhePhos & $\begin{array}{l}\text { s } 6,6^{\prime}\left[\left(3,3^{\prime}-\text { Di-tert-butyl-5, } 5^{\prime} \text {-dimehtoxy-1, }\right.\right. \\
\left.1^{\prime}-\text { biphenyl-2, 2'diyl)bis(oxy) }\right] \text { bis (dibenzo }[\mathrm{d}, \mathrm{f}][1,3,2]\end{array}$ \\
\hline & dioxaphosphepin \\
\hline CFD & computational fluid dynamics \\
\hline CSTR & continuously stirred tank reactor \\
\hline DHR & dihydroresorufin \\
\hline nC12an & dodecane \\
\hline iC13al & isomeric aldehydes \\
\hline 1C12en & 1-dodecene \\
\hline Dec. & decanter \\
\hline iC12en & isomeric dodecenes \\
\hline DMF & n,n-dimethylformamide \\
\hline expe. & experimental \\
\hline G1 & geometry 1 \\
\hline G2 & geometry 2 \\
\hline GC & gas chromatograph \\
\hline GC/MS & gas-chromatograph coupled to a mass spectrometer \\
\hline HCTR & helically coiled tubular reactor \\
\hline liq & liquid \\
\hline $\max$ & maximum \\
\hline num. & numerical \\
\hline opt & optimal \\
\hline param. & parameter \\
\hline PFR & plug flow reactor \\
\hline Ref. & reference \\
\hline $\mathrm{Rh}$ & rhodium \\
\hline TMS & thermomorphic multiphase system \\
\hline nC13al & tridecanal \\
\hline tot & total \\
\hline
\end{tabular}

Greek symbols

$\delta \quad$ curvature ratio $\delta=\frac{d}{D}$

the presence of a catalyst. Nowadays, mostly rhodium is used as catalyst, because it features a higher activity at milder reaction conditions compared to cobalt [1]. However, as rhodium is quite expensive, a lot of effort was taken to develop techniques for an efficient catalyst recycling. In this work a thermomorphic multiphase system (TMS) [2] is used to separate the catalyst from the products/reactants after the reaction. The usage of the TMS enables to perform the reaction in a single homogeneous liquid phase. Hence no mass transfer limitations occur, especially, if long chain olefines, like dodecene, are used. The hydroformylation of 1-dodecene in a TMS was subject of many publications in the last few years $[5-7,11,15,22,26,27]$. All these studies have been carried out in a CSTR, which is the classical heuristical choice for a slow gas-liquid reaction like the hydroformylation.

In contrast to former studies, a tandem reactor system, suggested by Kaiser et al. [13], is used in this work. The reactor system consists of a helically coiled tubular reactor (HCTR) connected to a continuous stirred tank reactor (CSTR) and was derived by an extensive modelbased reactor synthesis and dimensioning study, for an already existing miniplant, optimizing the selectivity with respect to the linear aldehyde, tridecanal. This tandem reactor system was constructed, integrated into a miniplant setup and firstly operated in this work. Furthermore, a detailed hydrodynamic study was carried out to verify the assumptions made by Kaiser et al. [13] during the reactor dimensioning. The hydrodynamic study was focused on the HCTR, as the assumptions regarding the micro- and macro-mixing in this reactor were more difficult to realize in practice. The influence of the helix
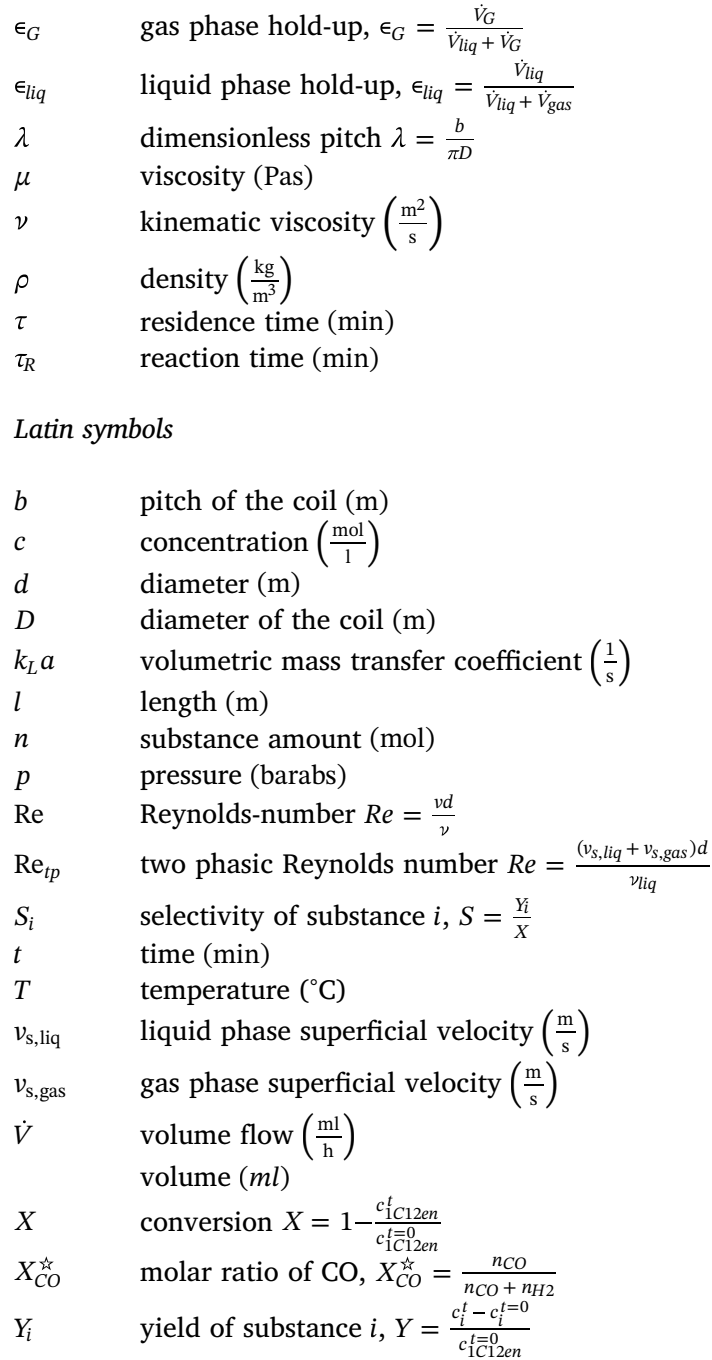

geometry parameters and the fluid properties on mixing was studied numerically using computational fluid dynamics (CFD). Furthermore the gas-liquid mass transfer progress was investigated experimentally in a locally and temporally resolved manner. For the operation of the tandem reactor system, optimal parameters were determined by optimization based calculations, taking the restrictions of the constructed reactors into account. Furthermore, this experiment was designed to be comparable to published results by using the same total residence time as well as catalyst and ligand concentrations. Finally, all results of this study will be compared to the assumptions made by Kaiser et al. [13] during the reactor synthesis and dimensioning procedure.

In short, the paper is organized as follows. First, the theoretical background to the hydroformylation reaction and the catalyst recovery technique, used in this work, are described. Next, the reactor dimensioning study of Kaiser et al. [13] is shortly reviewed. In Section 3, details of the construction of the HCTR + CSTR-tandem and the extension to an integrated miniplant setup are given. The hydrodynamic study of the HCTR is described in Section 4. In Section 5, the parameters for the operation of the miniplant are determined and the results of the experiments are presented. In the last section, all results of this study are summarized and compared to the assumptions of Kaiser et al. [13], in order to validate the model based reactor synthesis and dimensioning approach. 


\section{Background}

In the following section, more details to the hydrofrmylation reaction and the used TMS are given. In the second part, the reactor design study of Kaiser et al. [13] is shortly reviewed, as it is the theoretical basis for this study.

\subsection{Hydroformylation reaction and catalyst recovery}

As mentioned in the former section, the hydroformylation of 1-dodecene, using a TMS for the catalyst recovery, was topic of many previous studies. Hence, detailed information on the reaction network and kinetics are available. The reaction network, shown in Fig. 1, and the kinetics were determined by Kiedorf et al. [15] and later refined by Hentschel et al. [11]. The main reaction of the network in Fig. 1 is the hydroformylation to tridecanal. Moreover, strongly depending on the reaction temperature and the partial pressures of the gas phase, the side reactions to isomeric dodecenes and dodecane take place. The branched counterpart of the linear aldehyde can be synthesized, too. Due to their lower biodegradability, the branched aldehydes are undesired. Therefore, a high selective ligand, BiPhePhos, is used to suppress this reaction [22]. A high selectivity to the linear aldehyde has furthermore the advantage, that no distillation column for the separation of these isomers is required, which leads to lower investment and operation costs of a full production plant [10].

The composition of the TMS was determined by Schäfer et al. [24] and Brunsch and Behr [5] to minimize the leaching of the expensive rhodium/BiPhePhos catalyst. The solvent system consists of three substances with different polarities: N-decane ( $42 \mathrm{wt} \%$ ), as nonpolar solvent, 1-dodecene (16 wt\%), as semipolar solvent and reactant, and n,n-dimehtylformamide (DMF, $42 \mathrm{wt} \%$ ) as polar solvent. This composition has been chosen in a way, that the TMS forms a homogeneous liquid phase at the reaction temperature $\left(>85^{\circ} \mathrm{C}\right)$ and two separate phases (polar and nonpolar) at room temperature. As the polar rhodium/BiPhePhos catalyst is only soluble in the polar DMF-phase, it can be separated from the products and reactants, which are dissolved in the nonploar phase. Through the usage of this technique, a catalyst leaching rate of 3-5 ppm can be achieved [6].

\subsection{Tandem reactor system design}

The tandem reactor system for the presented hydroformylation reaction was derived by Kaiser et al. [13] using the flux profile analysis [14]. As core of this analysis, an arbitrary matter element is tracked on its way through the process. By optimally controlling external mass and energy fluxes to the matter element its optimal path in the thermoydnamic state space is determined. From these control profiles, reactor network candidates with integrated recycles are determined [14]. The flux profile analysis for the hydroformylation reaction was carried out aiming at the maximization of the selectivity with respect to the linear aldehyde, tridecanal, at high conversions of 1-dodecene ( $X \geq 90 \%)$. The results indicate that a tandem of a plug flow reactor (PFR), with distributed gas dosing and temperature control, and a continuous stirred tank reactor (CSTR) provides the highest performance. In the first reactor a reaction section of fast hydroformylation and isomerization is realized, which requires moderately high mass transfer rates and suffers from backmixing, whereas in the second reactor the synthesis gas ratio and the temperature are changed favoring a slow reverse-isomerization which benefits from backmixing. This second reaction section provides additional reactant for the hydroformylation reaction leading to an increased selectivity with respect to tridecanal. A sensitivity analysis with respect to the number of control inputs for the partial pressures in the PFR revealed that an initial dosing of synthesis gas, with a specific ratio, suffices to approximate the optimal control profiles properly. Main focus of the technical realization was put on the PFR, since the required mass transfer rates and plug flow behavior are more challenging to realize than the required conditions of the CSTR. Based on additional sensitivity analysis, the minimum value for the required volumetric mass transfer coefficient and a maximum allowed axial dispersion in the PFR maintaining an accurate approximation of the optimal performance have been determined. The intermittent flow regime was identified to be the most promising gas-liquid flow regime for the technical realization of the PFR. The intermittence of the liquid slugs ensure low axial dispersion, and internal circulation in the liquid slugs as well as high gas-liquid interphase areas due to the thin liquid wall film enhance the mass transfer [23,9]. To guarantee the formation of this flow pattern, an appropriate tube diameter had to be identified. Therefore, preliminary experiments were carried out using, for the sake of safety reasons, two substitute liquids, water and 2-propanol, and air as gas phase. These liquid components have been chosen featuring a higher and lower surface tension and density as the reaction mixture. The experimental results indicated the use of a maximum tube diameter of $d_{\text {tube }}^{\max }=3 \mathrm{~mm}$ to ensure the stable formation of an intermittent flow regime for the required volumetric flow rates (see Supplementary material of Kaiser et al. [13]. With this tube diameter and the required volume of $V_{R}^{P F R} \approx 2200 \mathrm{ml}$ a total length of approximately $311 \mathrm{~m}$ results. Coiling of this tube was suggested, in order to build a compact rig.

\section{Construction and miniplant integration of the tandem reactor system}

Based on the specifications from Kaiser et al. [13], the HCTR + CSTR system was constructed. In the following section, the construction of both reactors and their integration into a miniplant setup are described.

\subsection{HCTR}

The technical information provided by Kaiser et al. [13], are used for the construction of the HCTR. They suggested a maximum tube diameter of $d_{\text {tube }}^{\max }=3 \mathrm{~mm}$, thus a $3 / 16 \times 0.035$ inch stainless steel tube (TP316L) was chosen. The total reactor length was specified with $311 \mathrm{~m}$. Hence, a rather big coil diameter is needed to realize a compact reactor. For in-house manufacturing reasons, the coil diameter was limited to a maximum of $0.32 \mathrm{~m}$. As no coil diameter was mentioned by Kaiser et al. [13], it was decided to use an aluminum tube with a diameter of $0.306 \mathrm{~m}$. With this coil diameter, the HCTR-rig has a height of $2 \mathrm{~m}$. For the characterization of the reaction progress, eight sampling spots were integrated into the tube in logarithmic-scaled distances from the inlet. Moreover, the HCTR was constructed in a way that allows to shorten the reactor after discrete lengths. This enables more flexibility regarding the residence time inside the HCTR for the experiments.

As only initial synthesis gas dosing into the HCTR revealed to be sufficient [13], the gas is fed via a T-junction at the inlet into the coiled

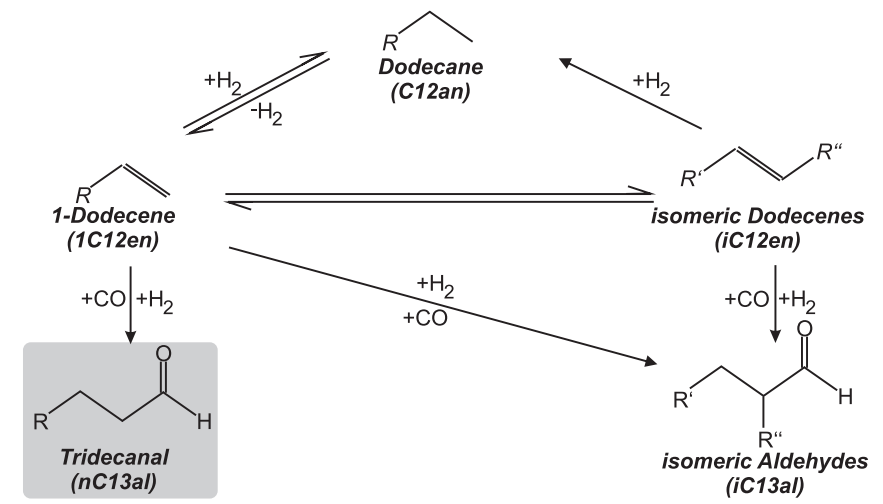

Fig. 1. Hydroformylation reaction network of 1-dodecene adopted from Hentschel et al. [11]. 
reactor. For the regulation of the $\mathrm{CO}$ and $\mathrm{H}_{2}$ feed streams, two mass flow controllers (Brooks ${ }^{\circledR}$ Instrument, SLA5800) are used. Regarding the frictional pressure loss inside the HCTR, preliminary experiments were performed by Kaiser et al. [13], which indicated a pressure loss of about $\Delta p \approx 0.53$ bar. However, the main pressure loss is caused by the gas consumption of the chemical reaction. Furthermore, the HCTR will be connected to the CSTR, where a separate gas dosing will be installed for the realization of different partial pressures. Since it is not possible to transfer the reaction mixture form the HCTR into the CSTR, which is then operated at a higher pressure, a back pressure regulator (Swagelok ${ }^{\star}$, series KPP) was installed at the HCTR-outlet.

Kaiser et al. [13] suggested heating tapes, through which different temperature zones along the reactor can be realized. Therefor, four special made heating shelves (Horst $\mathrm{GmbH}$ ) were installed. Due to the nature of the solvent system, all pipes through which the TMS is pumped trough have to be heated to a temperature of $>85^{\circ} \mathrm{C}$, to keep the reaction mixture single phasic. Consequently, electric heating ducts (Horst $\mathrm{GmbH}$ ) were wrapped around these pipes. For the control of all electronic devices, a process control system based on the Siemens PCS7 (V.8.1) was programmed.

\subsection{CSTR}

In contrast to the construction of the HCTR, the CSTR was rather simple to construct. Since the reactor in Kaiser et al. [13] was specifically designed for the miniplant setup of Dreimann et al. [6,7], where a CSTR was already present, the design of the reactor used in this study was adopted from the setup of Dreimann et al. [6,7]. The CSTR was realized using a pressure vessel (Büchi vesoclave type 4) with a total volume of $1000 \mathrm{ml}$ and a gassing stirrer $(650 \mathrm{rpm})$ for the intensification of the gas-liquid contacting. Similar to the HCTR, two mass flow controllers (Brooks ${ }^{\circledast}$ Instrument, SLA5800) are used to adjust the gas feeds into the reactor. For the pressure control, a back pressure controller from Brooks ${ }^{\circledR}$ Instrument (SLA5820) was installed. The jacketed CSTR was heated by an external thermostat (Julabo GmbH, F32). In contrast to the CSTR-design used by Dreimann et al. [6,7], no overflow pipe is used in the present reactor to fix the liquid level inside. Instead, a liquid mass flow controller (Bronkhorst High-Tech B.V., Cori Flow RHM015) was installed, to regulate the outlet stream. This mass flow controller was heated by an electric heating duct (Horst GmbH). Through integrated sight glasses in the CSTR, the liquid level could be observed, too. The same Siemens PCS7 (V.8.1) process control system, as for the HCTR, was used for the CSTR.

\subsection{Miniplant integration of the HCTR and CSTR}

The reactors, described in the two former sections, were combined with a decanter in order to construct an integrated miniplant setup (see Fig. 2). The decanter is used for the phase separation of the TMS in order to close the catalyst recycle stream. As this separation of the TMS has to be performed in a pressurized vessel, a Büchi vesoclave type 4 $(V=1000 \mathrm{ml})$ is used for the decantation. To promote the separation of the two phases, barrier installations were made inside the vessel. The gas feed streams and the temperature in the decanter were controlled by two mass flow controllers (Brooks ${ }^{\circledR}$ Instrument, SLA5800) and a thermostat (Julabo GmbH, CF31), respectively, similar to the CSTR. A back pressure regulator (Swagelok ${ }^{\circledR}$, series KPP) was installed for the regulation of the vessel pressure. Sight glasses decanter enable an observation of the phase boundary between the catalyst containing phase and the product/reactant phase. To prevent an overfilling of the decanter, a liquid detector (ACS-control-system GmbH, Vibrocont SCM352) was installed in the vessel. The product phase was pumped out of the decanter with a piston pump (KNAUER Wissenschaftliche Geräte GmbH, AZURA P4.1). A relief valve (Swagelok ${ }^{\circledR}$ R-Series) was used to compensate the pressure difference between decanter and atmosphere. The catalyst phase was pumped (KNAUER Wissenschaftliche Geräte
GmbH, AZURA P4.1) from the bottom of the vessel back into the HCTR. A mass flow meter (Bronkhorst High-Tech B.V., Cori Flow RHM015) was installed to monitor the mass flux of this recycle stream. The feed streams (n-decane, 1-dodecane and DMF-make-up) of the miniplant were fed into the HCTR via piston pumps (KNAUER Wissenschaftliche Geräte $\mathrm{GmbH}$, Smartline 1050). The fluxes of the inlet and outlet streams were monitored via the weighing (Sartorius AG, LP12000S; Mettler-Toledo GmbH, MS4002TS) of the storage vessels. All electronic devices of the miniplant setup were also operated form the Siemens PCS7 (V.8.1) process control system.

\section{HCTR characterization}

In practice, it is very unusual to use a tubular reactor for a gas-liquid reaction. Since many assumptions were made during the reactor dimensioning procedure and the construction of the HCTR, a detailed hydrodynamic study was performed. The CSTR will not be regarded in this study, because the reaction engineering and fluid mechanic phenomena of stirred tanks are well understood.

Due to the size of the HCTR, and the fact, that the reactor is manufactured from stainless steel, smaller and transparent model geometries, denoted as G1 and G2 (see Fig. 3) were applied for this hydrodynamic characterization, because the employed optical experimental methods imply transparent tube walls. Compared to the HCTR, the model geometries have higher curvature ratios $(\delta=d / D)$ and bigger dimensionless pitches $(\lambda=b / \pi D)$, due to the much smaller coil and bigger tube diameters as well as bigger pitches (see Table 1 ). For safety reasons and the fact that the TMS is two phasic at temperatures $<85^{\circ} \mathrm{C}$, water $\left(\rho=998.2 \mathrm{~kg} / \mathrm{m}^{3}, \mu=1.003 \times 10^{-3}\right.$ Pas [25]) was used in the model geometries instead of the TMS ( $\rho=773.3 \mathrm{~kg} / \mathrm{m}^{3}, \mu=3.74 \times 10^{-3}$ Pas). However, as the outcome of this study confirms, the influence of these geometrical and fluid parameters on mixing as well as the gas-liquid mass transfer is much smaller than the impact of the Reynolds-number. Therefore, the results from the model geometries can be transferred to the HCTR as the same Renumbers were employed.

\subsection{Mixing inside the liquid phase}

Mixing was examined numerically in the HCTR geometry, using the fluid properties of the TMS, and in geometry G1, applying the water fluid properties, with parameter variations of the pitch $b$ and the curvature ratio $\delta$. Similar to former investigations, the CFD code StarCCM + was used [12,19-21].

For the study, a vertical separation of two liquids in a fully developed laminar pipe flow is admitted at the inlet. The obtained mixing efficiency, defined like in Mansour et al. [19], where 0 indicates no mixing and 1 stands for full mixing, are shown in Fig. 4 along the helix

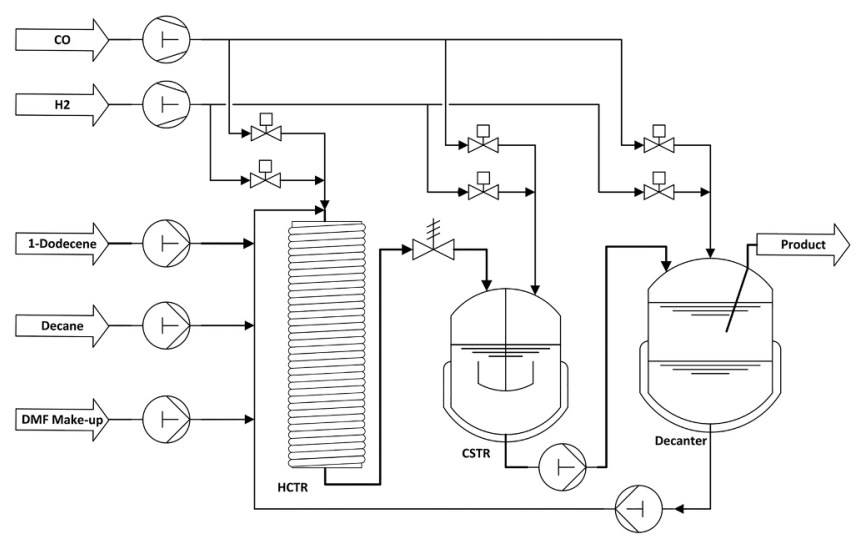

Fig. 2. Simplified flow chart of the miniplant setup. 
main axis in geometry G1 and for a Reynolds-number of 100. It is obvious from Fig. 4, that mixing is nearly complete after slightly more than $1 / 5$ of the total helix length, which means for the geometry used here after one turn. A small, local oscillation of the mixing coefficient can be observed at $X / L=0.1$, which is caused by the secondary flow pattern and is typical for such mixing processes in helical coils.

The rapid mixing becomes also visible in the concentration plots in Fig. 5 for geometry G1 (top) and the HCTR-geometry (bottom). Starting from the inlet $\left(0^{\circ}\right)$, the mass fraction is shown for different positions along the coiled tube. After one turn $\left(360^{\circ}\right)$, the mixing is rather complete and only slight changes can be recognized after two $\left(720^{\circ}\right)$ and three turns $\left(1080^{\circ}\right)$ of the tube. This effect is slightly stronger in the HCTR.

By varying the Re-number and looking on the outlet mixing efficiency for different curvature ratios and dimensionless pitches for G1 in Fig. 6, different conclusions can be drawn. First of all, two maxima for the mixing efficiency can be recognized on all of these curves at about $\operatorname{Re}_{1}=40$ and $\operatorname{Re}_{2}=750$, which do not depend strongly on the geometrical parameters. Between these Re-numbers, the amount of mixing is nearly the same for all geometries. The tube diameter, coil diameter and pitch have only a major impact on the mixing efficiency, if the Renumber is smaller than 30 or bigger than 1000 . This means for the HCTR, that the geometrical parameters have no big influence on the mixing efficiency, because the HCTR is operated at Re-numbers of around 105. This is underlined by the results shown in Fig. 5 and the results for mixing efficiency of the HTCR at different Re-numbers also depicted in Fig. 6 with triangles. These curves show a slight shift to higher Re-numbers for the domain of highest mixing efficiencies, that can be explained by the different fluid properties. However, the HCTR is operated at Re-numbers between 98 and 113, hence the fluid properties have no major impact on the mixing and mixing efficiency attains nearly $100 \%$. This shows, that the transfer of the results obtained in the smaller model geometries to the bigger HCTR-geometry is possible. Responsible for this intensified mixing characteristics and also for the enhanced mass transfer, as will be shown in the next section, are the secondary flow pattern inside the helical tube. These Dean-vortices can be visualized from 3D-velocity measurements [17] and from the calculated velocity fields [21] as shown in Fig. 7.

\subsection{Gas-liquid mass transfer}

The mass transfer measurements were carried out locally and temporally resolved with the oxygen sensitive dye resazurin. Therefore, resazurin $(43.5 \mathrm{mg} / \mathrm{l})$ is first reduced in a aqueous solution of sodium hydroxide $(9.6 \mathrm{~g} / \mathrm{l})$ and glucose $(17.4 \mathrm{~g} / \mathrm{l})$ to the colorless dihydroresofurin (DHR). In the presence of oxygen, the colorless DHR is oxidized to pink-colored resofurin. As this oxydation reaction is reversible, the tracer solution was adjusted in a way, that the oxidation reaction is quasi instantaneous, whereas the reduction reaction lasts for several minutes. The intensity of the colored substance was measured by colorimetry with a high-speed camera. Hence, the color of the saturated pink solution at a known colorant concentration $c_{\text {col }}$ can be associated to an equivalent oxygen concentration $c_{\mathrm{O} 2}$ in the solution. The calculated concentration is only an equivalent concentration, because no oxygen is actually dissolved, due to the reaction. For the mass transfer characterization, the transparent geometry G2, made from glass, was used. Air was injected directly at the first turn of the helix through a capillary, with an inner diameter of $0.2 \mathrm{~mm}$, fixed concentrically at the helix inlet. The initial oxygen-free, transparent solution was pumped from a tank through the helical reactor into a waste container. The color change was observed with a high speed camera Imager Pro HS $4 \mathrm{M}$ from LaVision (K) with a frame rate of $100 \mathrm{~Hz} .3000$ images were taken for each experimental condition to get a statistically relevant mean image of the color change. From these images, the reaction progress and the equivalent oxygen concentration, but also volumetric mass transfer coefficients were determined. Further details of the setup and data evaluation procedure can be found in Kováts et al. [16,18].

Fig. 8 illustrates the equivalent oxygen concentrations in the helix reactor for all examined gas hold-ups $\left(\varepsilon_{\mathrm{G}}\right)$ and two different superficial liquid velocities in the intermittent flow regime. The saturation concentration was almost reached during the first seconds of residence time or within the first 3-4 turns of the helix. The increase of the gas hold-up leads to higher mass transfer rates, whereas the liquid superficial velocity () has no significant influence on the oxygen concentration in the liquid phase.

The volumetric mass transfer coefficients $\left(k_{L} a\right)$ were calculated from the measured oxygen concentrations and are shown in Fig. 9. The liquid velocity has no big influence on the volumetric mass transfer coefficient, as already depicted in the previous Fig. 8. However, a higher gas hold-up always leads to bigger $k_{L} a$-values, especially during the first second of residence time. Afterwards, all curves collapse to $k_{L} a$-values of around $0.21 / \mathrm{s}$ due to the approaching saturation.

\section{Miniplant experiment}

The operational parameters for the miniplant experiments are determined by using the model of Kaiser et al. [13], without the flash and distillation column. Moreover, the experimental results for these operational parameters are discussed.

\subsection{Determination of the operation parameter}

In order to predict the optimal control inputs for the experimental investigation, dynamic optimization calculations are carried out under the specific conditions and constraints of the constructed miniplant setup, see Table 2. As the performance of the tandem reactor system, used in this work, is supposed to be compared to the miniplant of Dreimann et al. [6], containing only a single CSTR, the residence time of $\tau=210 \mathrm{~min}$ in the reaction section is chosen to be equal in this experiment. The volume and the liquid hold-up of the CSTR unit in the HCTR + CSTR tandem are adopted from the miniplant setup of Dreimann et al. [6]. Due to the usage of two reactors, the total reaction volume of the miniplant increases. Therefore, the total volumetric flow rate has to be increased in order to realize the same residence time like Dreimann et al. [6] used in their work. The volumetric flow rate of the tandem reactor system is set to $\dot{V}_{\text {liq }}^{\text {opt }}=150 \mathrm{ml} / \mathrm{h}$ which corresponds to 1.5 times the flow rate used by Dreimann et al. [6]. This results in a liquid phase volume in the HCTR of $V_{\text {liq }}^{\mathrm{HCTR}} \approx 195 \mathrm{ml}$. Assuming a liquid hold-up of $\epsilon_{\text {liq }}^{\mathrm{HCTR}} \approx 0.33$ as suggested by Kaiser et al. [13], the HCTR volume is determined to $V_{\text {tot }}^{\mathrm{HCTR}} \approx 590 \mathrm{ml}$. Catalyst and ligand concentration were chosen to be the same as used by Dreimann et al. [6].

Note, that the original reactor-network synthesis and technical reactor dimensioning of Kaiser et al. [13] had been carried out for a

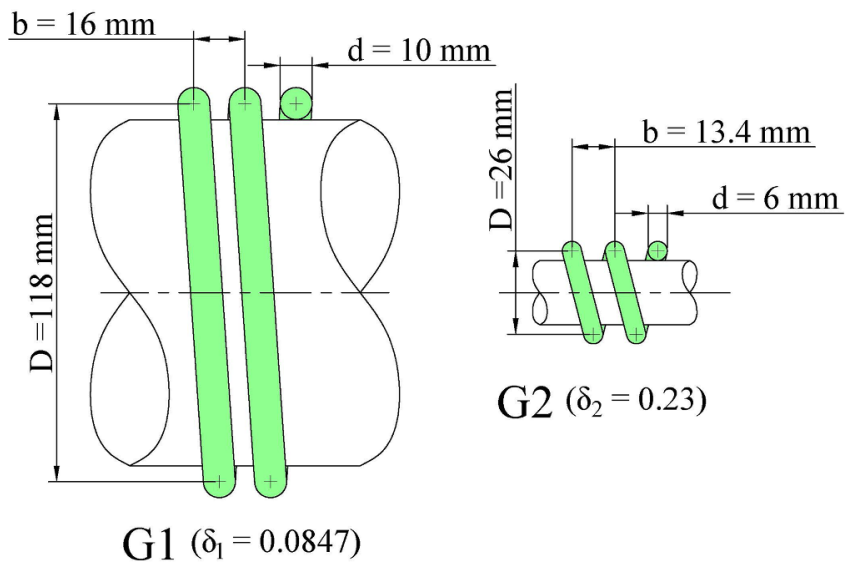

Fig. 3. Details of the helix geometries used for the numerical (G1) and experimental (G2) hydrodynamic study. 
Table 1

Nondimensionless parameters of the different geometries.

\begin{tabular}{cccc}
\hline Geometry & $\delta$ & $\lambda$ & $\operatorname{Re}_{t p}$ \\
\hline HCTR & 0.0096 & 0.0059 & $98 \ldots 113$ \\
G1 (num.) & 0.0847 & 0.0431 & 100 \\
G2 (expe.) & 0.23 & 0.164 & 136 \\
\hline
\end{tabular}

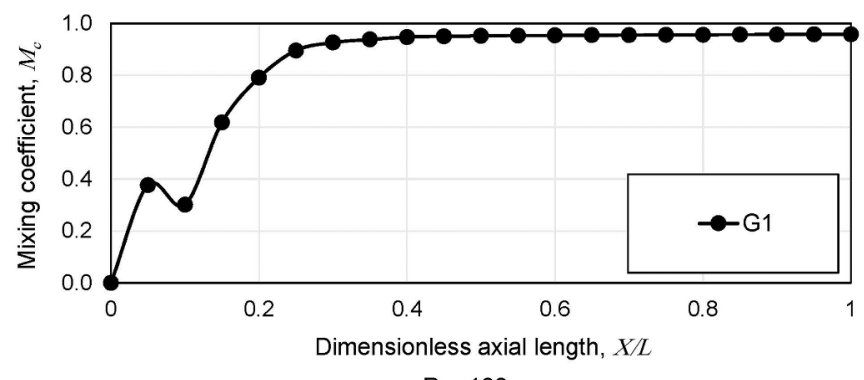

$\mathrm{Re}=100$

Fig. 4. Liquid mixing coefficient along the dimensionless helix axis at $\operatorname{Re}=100$ in geometry G1.

higher overall residence time. For the smaller residence time mentioned before, the reactor synthesis and dimensioning procedure indicated qualitatively the same results, whereby the first reactor only has to be shortened. Hence, the optimal reactor-network HCTR + CSTR reactor tandem and the requirements for both units stayed the same. For the present work, the optimal control inputs are recalculated for the operation of the reactor tandem.

In the HCTR, the synthesis gas is fed only at the inlet. Due to the reduced reactor length of the HCTR in the experiment $\left(l_{H C T R}^{\text {expe. }}=80 \mathrm{~m}\right)$, only two heating zones can be realized (see Table 2). The CSTR has a constant temperature and constant partial pressure levels. In addition to these control inputs, the results of these calculations indicate the sizes of the volumetric inlet and outlet streams, which serve as orientation for the experiment. The profiles of the control variables and the predicted reaction progress are illustrated in Fig. 10. The first section up to $t=78 \mathrm{~min}$ indicates the reaction in the HCTR, whereas the subsequent constant profiles correspond to the conditions inside the CSTR. From the concentration profiles in Fig. 10, a final selectivity with respect to tridecanal of $S_{n C 13 a l}=69 \%$ can be calculated at the final conversion of 1-dodecene of $X_{1 \text { C12en }}=99.5 \%$. A scheme of the HCTR + CSTR tandem with all relevant inlet and outlet streams as well as the control inputs is
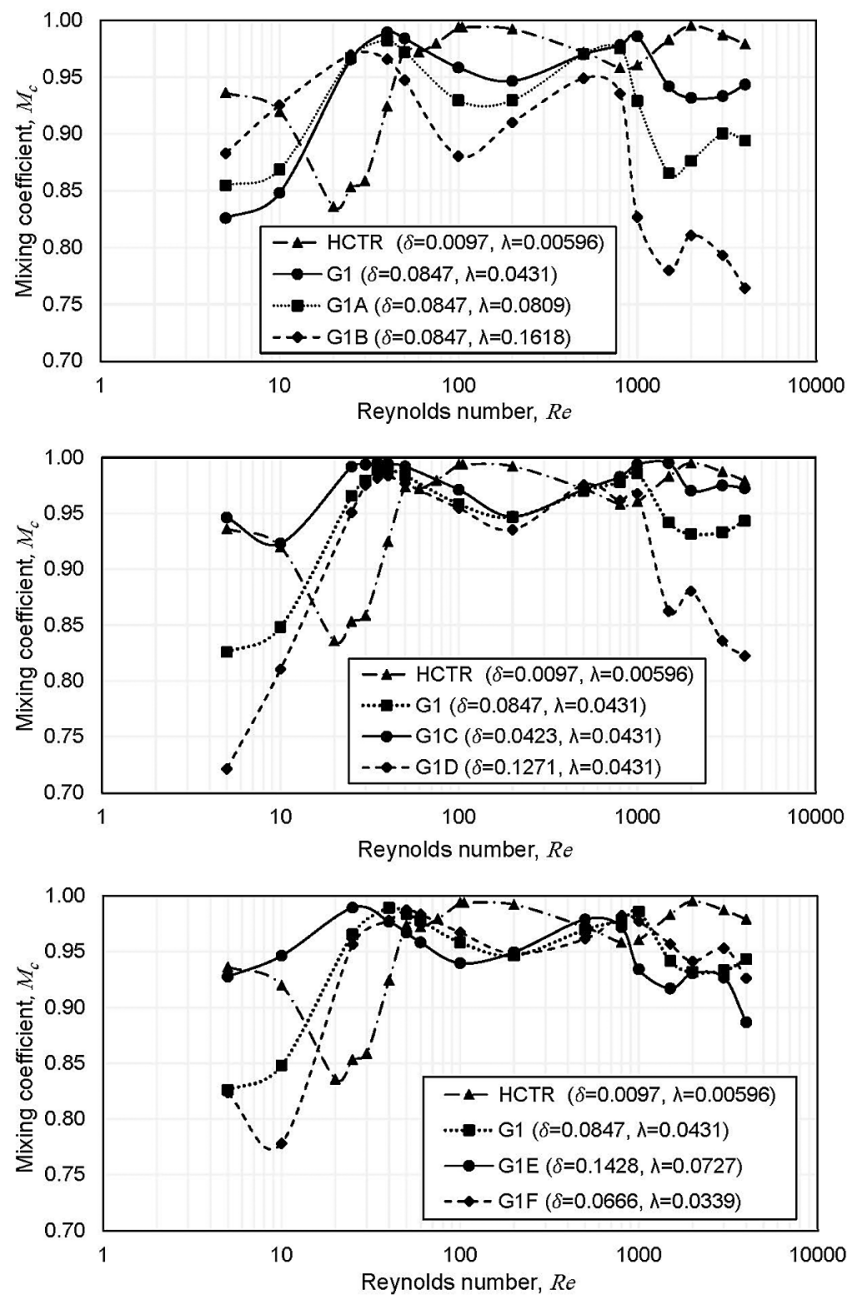

Fig. 6. Liquid mixing efficiency at the outlet for different Re-numbers in geometry G1 for water with variation of tube diameter $d$ (top), coil diameter $D$, (center) and pitch $b$ (bottom) and in the HTCR geometry with the TMS.

given in Fig. 11.

During the experiment, the influence of the reaction parameter (temperature, gas composition) on the reactant concentrations will be

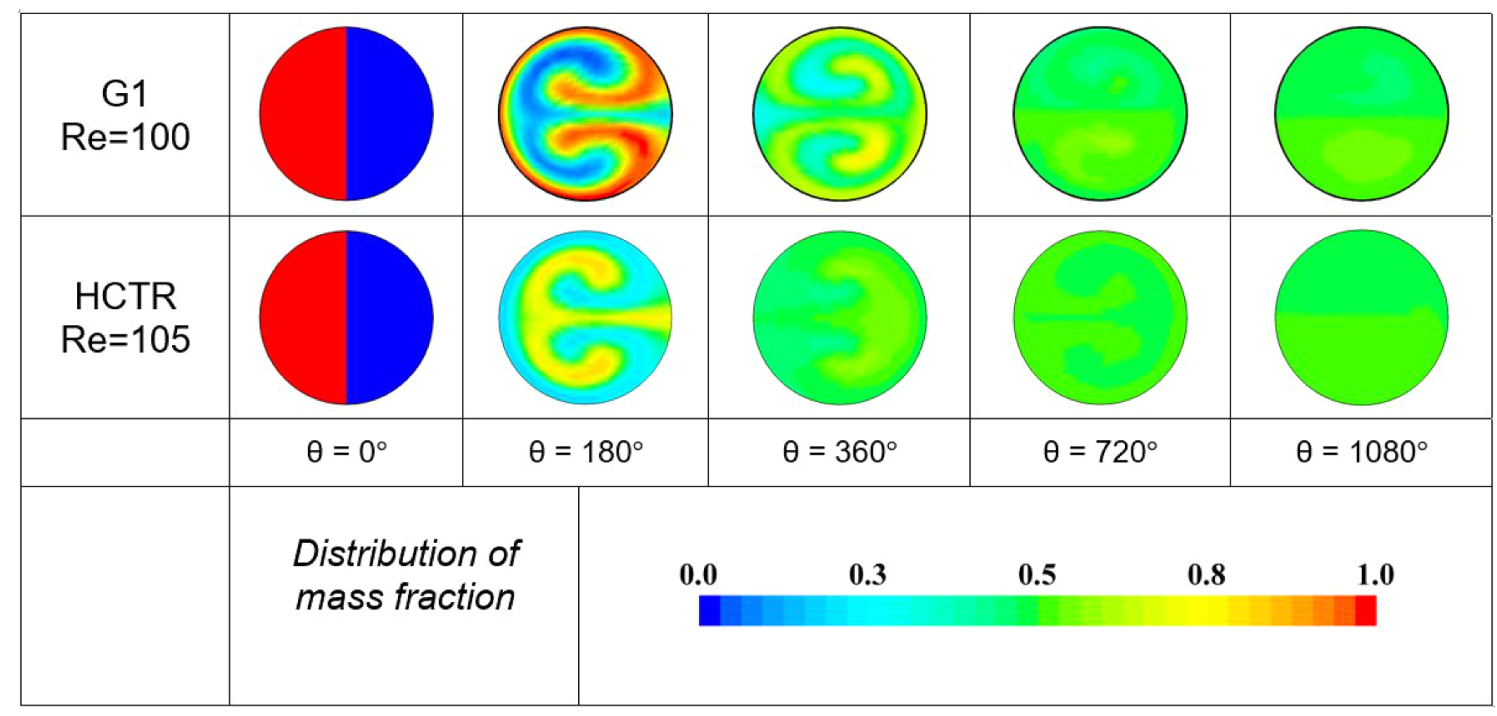

Fig. 5. Distribution of the liquid mixing mass fraction at different positions along the coil for geometry G1 and the HTCR. 


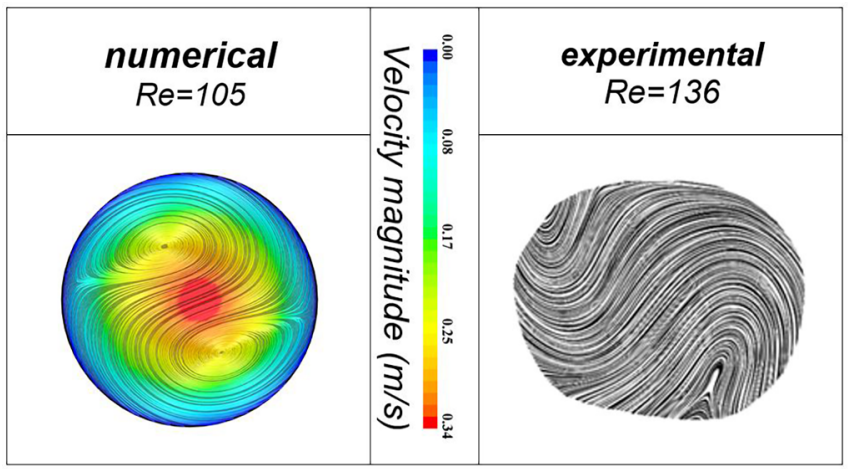

Fig. 7. Streamlines in perpendicular cuts through the helical tubes visualized from numerical calculations in the HCTR-geometry (left hand side, TMS fluid properties) and from experiments in G2 with water (right hand side).

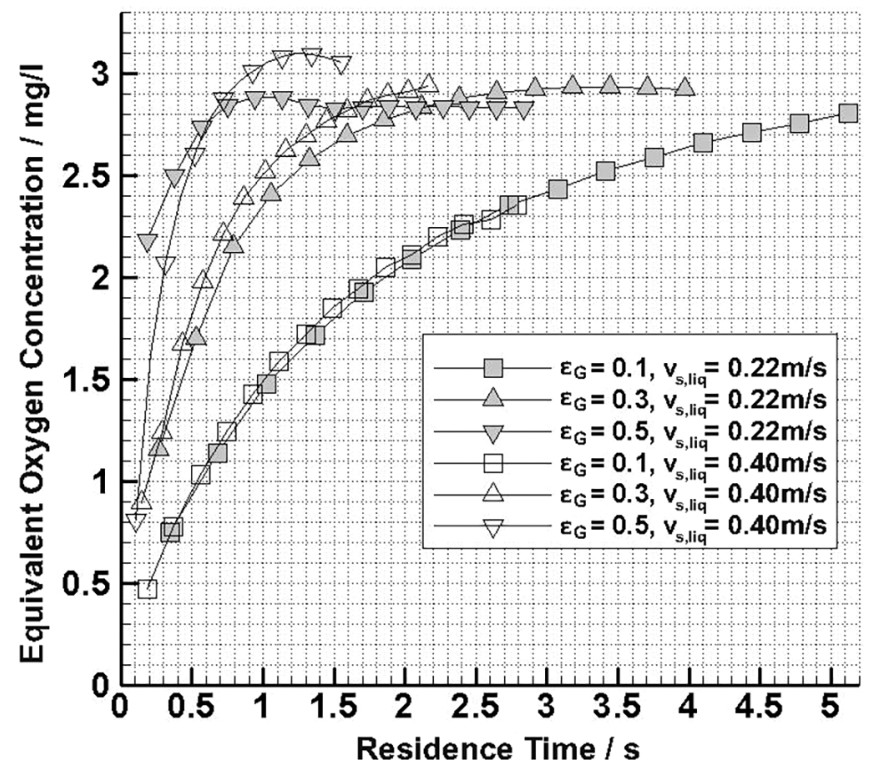

Fig. 8. Equivalent oxygen concentrations in the helix for different gas hold-ups and liquid superficial velocities.

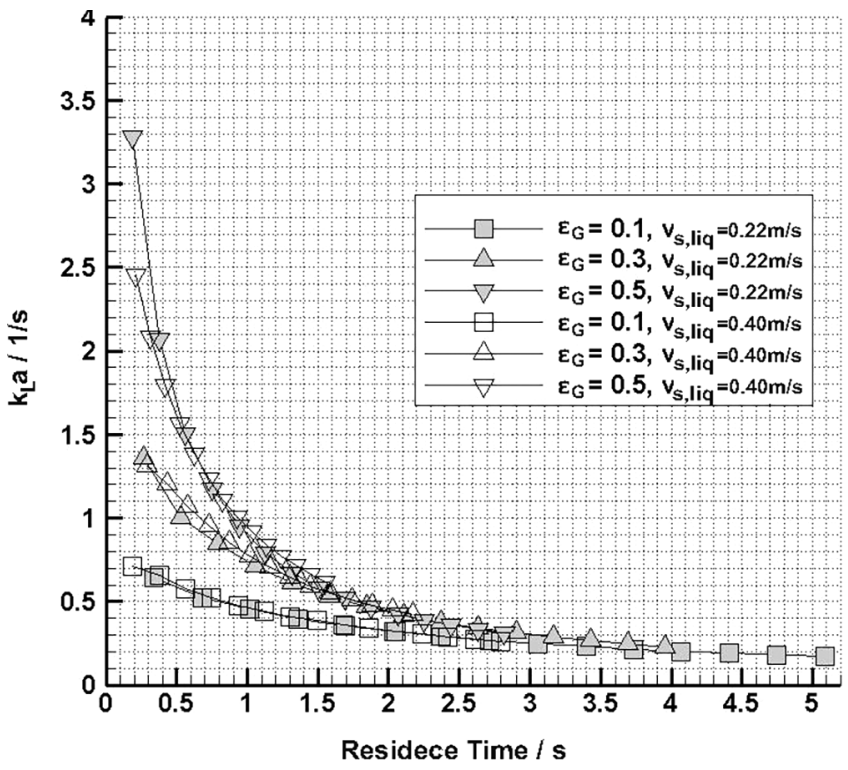

Fig. 9. Volumetric mass transfer coefficient $k_{L} a$ in the helix rector.
Table 2

Conditions and constraints of the technical realization.

\begin{tabular}{|c|c|c|}
\hline Parameter & & Restriction \\
\hline$p_{\mathrm{HCTR}, \mathrm{CSTR}, \mathrm{Dec} .}^{\text {tot }}$ & & $0 \ldots 21 \mathrm{bar}$ \\
\hline 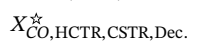 & & $0 \ldots 1$ \\
\hline$l_{T 1, \mathrm{HCTR}}$ & & $66 \mathrm{~m}$ \\
\hline$l_{T 2, \mathrm{HCTR}}$ & & $105 \mathrm{~m}$ \\
\hline$l_{T 3, \mathrm{HCTR}}$ & & $95 \mathrm{~m}$ \\
\hline$l_{T 4, \mathrm{HCTR}}$ & & $24 \mathrm{~m}$ \\
\hline$l_{\mathrm{HCTR}}^{\text {tot }}$ & $l \in$ & {$\left[\begin{array}{c}3,5,9,14,21 \\
34,56,80,105 \\
130,153,166 \\
190,215,239 \\
264,289 \mathrm{~m}\end{array}\right]$} \\
\hline$T_{l=1 \ldots 4, \mathrm{HCTR}}$ & & $20 \ldots 120^{\circ} \mathrm{C}$ \\
\hline$T_{C S T R}$ & & $20 \ldots 120^{\circ} \mathrm{C}$ \\
\hline$T_{D e c}$ & & $5^{\circ} \mathrm{C}$ \\
\hline
\end{tabular}

studied. Hence, reference parameters will be applied for a short time span. Information on the used chemicals and analytics can be found in the supporting information.

\subsection{Miniplant results}

The miniplant setup shown in Fig. 2 was operated for $116 \mathrm{~h}$. The results of this experiment (Fig. 12) indicate a significant drop of the selectivity to tridecanal and increase of the isomeric aldeyhde production between 20 and 80 operation hours. Adding new BiPhePhos ligand to the make-up stream enhanced the selectivity to tridecanal, the amount of isomeric aldehydes dropped down and the selectivites are stable until the operation parameters were changed at hour 89 . There, the temperature inside the HCTR was changed to $105^{\circ} \mathrm{C}$ and the molar feed ratio of CO into the HCTR and CSTR were changed to 0.5, marked as Ref. parameters in Fig. 12. This was done in order to identify the influence of the optimally calculated reaction parameters on the reaction performance. The new reaction parameters declined the selectivity to tridecanal to 0.56 and the amount of isomeric dodecenes increased. At hour 102, the reaction parameters where changed back to the optimal ones, which immediately increased the selectivity to tridecanal. During the last $8 \mathrm{~h}$ no change of the selectivities has been observed anymore and hence, the miniplant finally reached its stable operation point. A final selectivity of 0.70 to tridecanal and a aldehyde n/iso-ratio of $98 / 2$ were gained. No 1-dodecene could be detected by the GC/MS at the outlet of the CSTR anymore, indicating that full conversion was achieved.

Additionally, during the experiment samples from the product phase were taken to measure the leaching of rhodium with inductively coupled plasma mass spectrometry. The results show a rhodium leaching between 1.56 and $2.26 \mathrm{ppm}$, which is lower than the leaching values of 3-5 ppm reported by Dreimann et al. [6].

After the experiment, 31P NMR-measurements of the BiPhePhos used until the operation hour 80 were done, because of the selectivity problems. Gerlach et al. [8] reported for the BiPhePhos and the same reaction system a big selectivity influence due to the oxidation of the ligand. Our analysis revealed, that the BiPhePhos was already partly oxidized before its usage and hence caused the selectivity problems.

In order to compare the reactor performance for the reference control parameters and the optimized control parameters in more detail, samples were taken from both reactors at around 100 operation hours and 114 operation hours, respectively. The resulting concentration profiles are shown in Fig. 13.

The depicted concentrations between $0 \mathrm{~min} \leqslant \tau_{R}<78 \mathrm{~min}$ are from samples taken from the HCTR, whereas the concentrations at $\tau_{R}=78 \mathrm{~min}$ and $\tau_{R}=210 \mathrm{~min}$ were measured at the inlet and outlet of the CSTR, respectively. In general, the concentration profiles for 

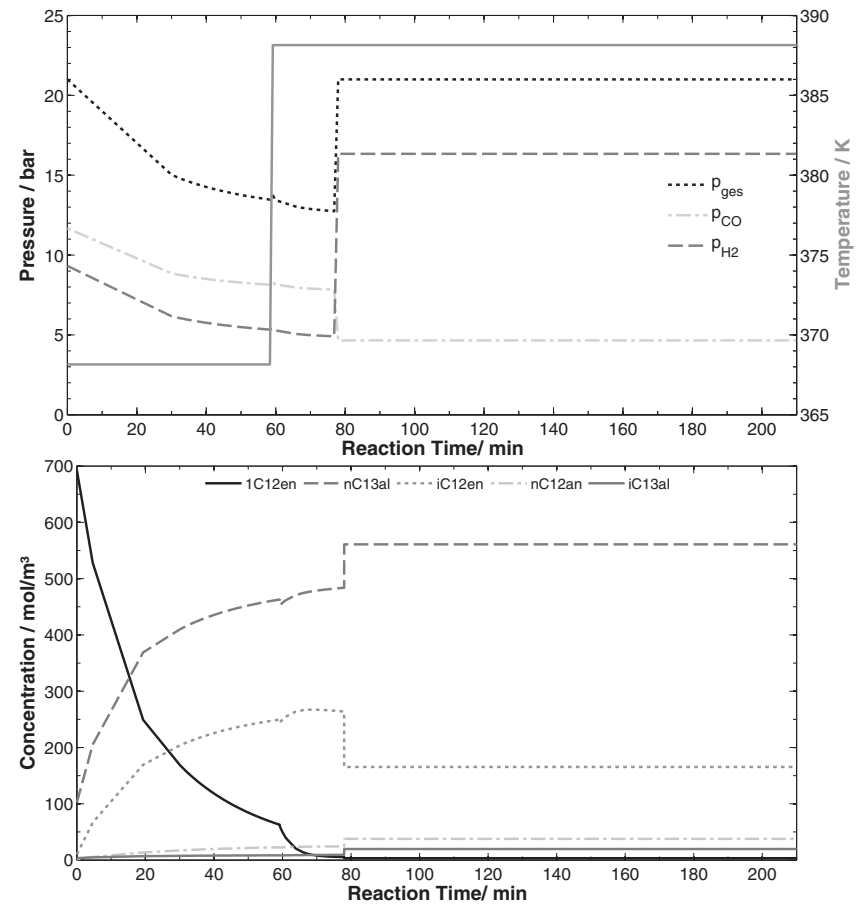

Fig. 10. Optimized control variables for the miniplant operation (top) and the predicted concentration profiles from the simulations (bottom).

tridecanal and dodecene isomers are similar for both cases. However, through the two temperature zones $\left(T_{1}=95^{\circ} \mathrm{C}, T_{2}=115^{\circ} \mathrm{C}\right)$ in the HCTR and the excess of hydrogen in the CSTR, higher tridecanal and lower dodecene isomer concentrations were measured at the CSTR outlet, when the optimal parameters were applied. Due to the lower temperature in the first zone, the hydroformylation reaction rate is enhanced, whereas the isomerization reaction rate is reduced. With increasing reaction time, the temperature in the HCTR increases and therefore the backisomerization reaction rate is enhanced which provides additional reactant for the hydroformylation reaction. For the reference parameters, an increased dodecene isomer concentration and less backisomerization results, because of the constant temperature $\left(T_{H C T R}=105^{\circ} \mathrm{C}\right)$ in the HCTR. The influence of the partial pressures in the HCTR are negligible, since similar molar ratios were used in both cases $\left(X_{C O}^{i}\right.$, opt $=0.54, X_{C O}^{\hat{L}}$,ref $\left.=0.50\right)$. In the CSTR, the same temperatures $\left(T_{C S T R}=115^{\circ} \mathrm{C}\right)$ were used with both parameter sets. However, due to the excess of hydrogen with the optimal parameters, the backisomerization is further enhanced, whereby the tridecanal concentration additionally increases. Summing up, the optimally calculated operation conditions, predicted by the flux profile analysis, significantly enhanced the tridecanal concentration.

\section{Reactor design validation}

In this section, the results of this study will be compared to the assumptions made by Kaiser et al. [13] in order to validate the reactor design approach. This analysis is focused on the HCTR, rather than the CSTR, because the latter one is a very common reactor type.

Kaiser et al. [13] fixed only the tube diameter and made no suggestions for a coil diameter or the coil pitch. In order to realize a compact reactor, a big coil diameter of $0.306 \mathrm{~m}$ was chosen. The results of the CFD study on the influence of the coil pitch and coil diameter showed, that these parameters have no major impact on the mixing within the coil, if the Reynolds-number is in the region between 40 and 750. This condition was fulfilled during the operation and will be fulfilled if the HCTR + CSTR tandem is operated with the higher flow rate used by Kaiser et al. [13] for the reactor dimensioning. Additionally, the mixing study revealed the formation of a secondary flow pattern due to the coiling of the tube, which further intensifies the mixing in the reactor. In general, the minor influence of the coil diameter and coil pitch on the mixing is a very valuable information for the dimensioning of helically coiled reactors.

Since the tandem reactor system is used for a gas-liquid reaction, the gas-liquid mass transfer is very important, especially within the tubular reactor. Kaiser et al. [13] assumed, that a minimum $k_{L} a$-value of $0.11 / \mathrm{s}$ is sufficient. The performed $k_{L} a$-measurements revealed a minimum value of $0.21 / \mathrm{s}$, hence the assumption is fulfilled.

As flow regime, the intermittent flow was suggested, as this regime features low axial backmixing and due to the internal circulation of the slugs enhanced mixing. In this study, the two phase flow regime was not explicitly verified. But during the GC-sampling out of the HCTR it was observed, that gas and liquid slugs leave the sampling pipe alternating. This is a very strong indicator, that the HCTR was actually operated in the intermittent flow regime. Through this flow regime, the axial backmixing is reduced to a minimum [23]. Therefore, no further study was made.

Fig. 14 shows the comparison between the predicted conversion and tridecanal selectivity and the experimental results along the reaction time. The predicted and experimental values of the final concentrations are in an excellent agreement. However, the conversion difference between the model prediction and the experiment is bigger within the first minutes of reaction time. The reason for this lies in the construction of the HCTR. Before the synthesis gas is fed to the reaction mixture, the mixture has already reaction temperature and hence, the catalyst isomerizes the 1-dodecene due to the lack of synthesis gas. This explains the slightly higher conversion in the experiment. The selectivity profiles of tridecanal are well predicted for the first stage of reaction, although a higher selectivity was reached experimentally as the mixture enters the CSTR after 78 min. Consequently, the impact of the CSTR on the tridecanal selectivity is a little lower than the model prediction indicates.

As last point of this validation, the experimental results of this study are compared to the study of Dreimann et al. [6], in order to verify, whether the reactor concept actually enhances the process performance. As mentioned before, the reactor design of Kaiser et al. [13] was specifically done for the miniplant of Dreimann et al. [6], where only a single CSTR is used as reactor. The comparison is valid, as the same TMS and residence time as well as catalyst and ligand concentrations were used in both studies. Dreimann et al. [6] reported a tridecanal yield of 0.64 and a conversion of 0.80 . In this work, a yield of 0.70 and full conversion were achieved. This means that the yield and conversion were enhanced by $25 \%$ and $9 \%$, resprecively, through the tandem reactor system.

The comparison between the results of this study and the assumptions made by Kaiser et al. [13] during the model based reactor synthesis and dimensioning revealed, that the decisions made during the dimensioning were right. Additionally, it was shown that the HCTR + CSTR system works with excellent performance in practice. Hence, it can be concluded, that the flux profile analysis design methodology developed by Kaiser et al. [13,14] works in practice and is a very powerful tool for the design of reactor-networks.

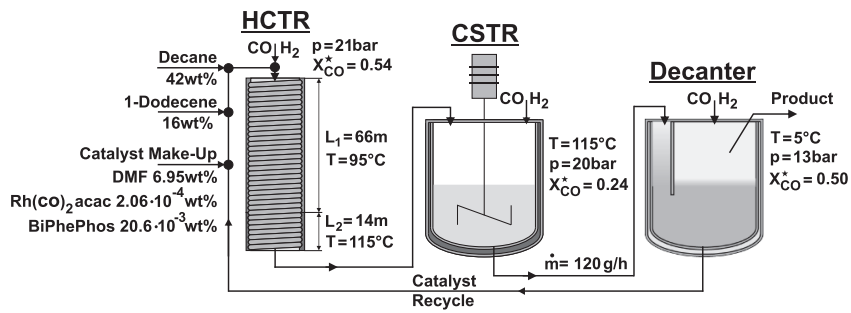

Fig. 11. Tandem reactor system including the inlet streams and the optimized parameters. 


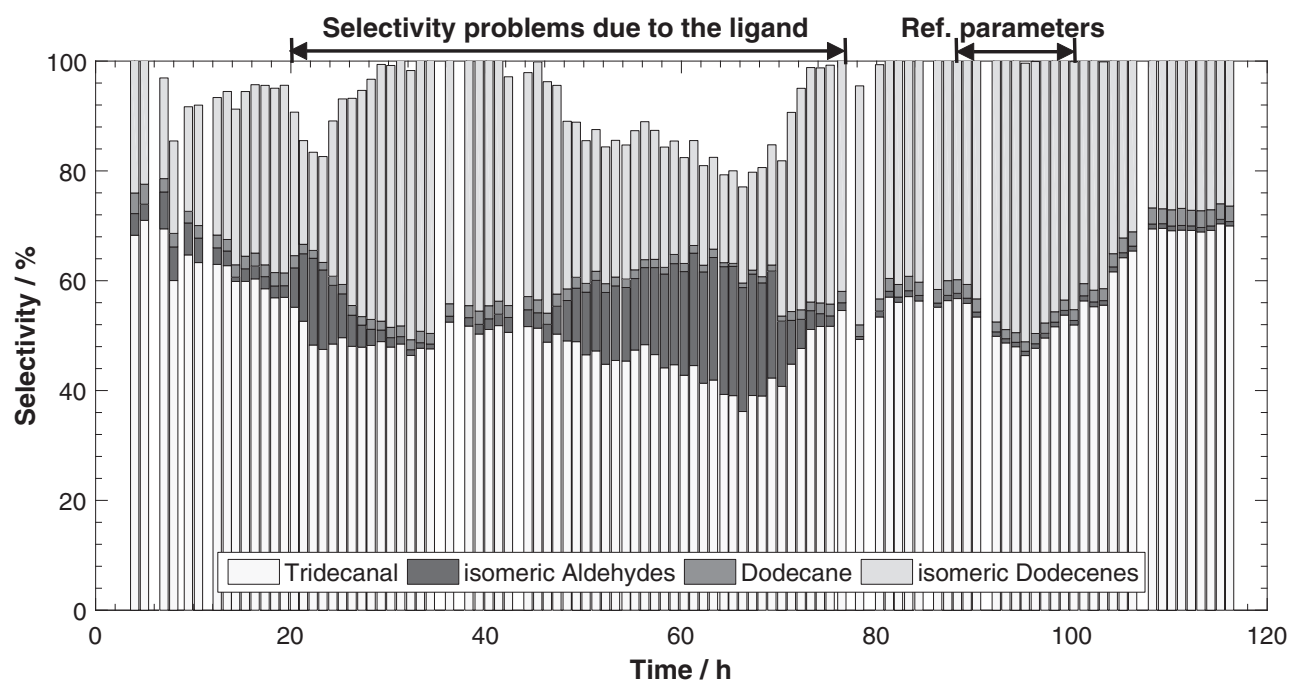

Fig. 12. Achieved selectivities during the miniplant experiment.

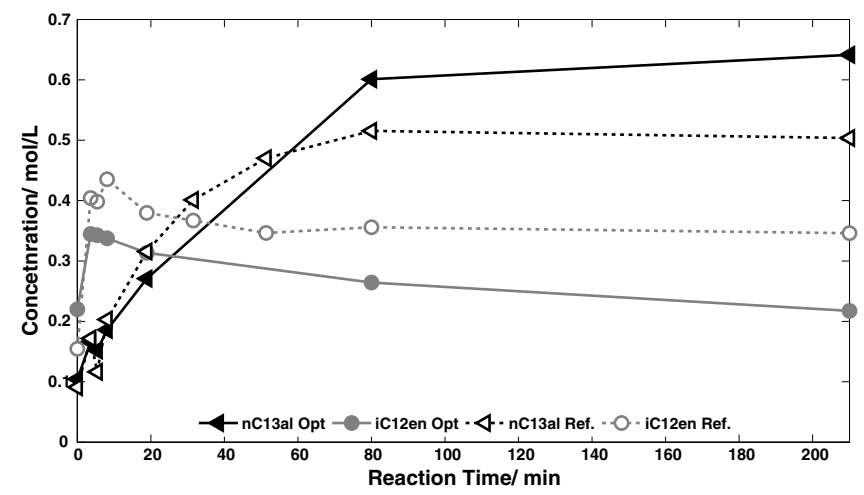

Fig. 13. Influence of the reaction temperature on the concentrations of tridecanal (nC13al) and isomeric dodecenes (iC12en) along the reaction time.

\section{Summary}

For the hydroformylation of 1-dodecene using a DMF/n-decane thermomorphic multiphase system for the recovery of the Rhodium/ BiPhePhos catalyst, an optimal reactor setup has been derived by Kaiser et al. [13] for an already existing miniplant. The resulting tandem reactor system, consisting of a helically coiled tubular reactor (HCTR) connected to a continuous stirred tank reactor (CSTR), was constructed and combined with a decanter firstly operated as well as characterized in this work. To validate the reactor design approach of Kaiser et al. [13] a detailed hydrodynamic study of the HCTR was performed. Thereby, the mixing inside the helix, the gas-liquid mass transfer and the influence of the geometrical parameters were studied on smaller model geometries. However, as the outcome of the study verifies, the transfer of the results to the HCTR was possible, as the study was performed in the same flow regime and Reynolds-numbers. For the operation of the HCTR + CSTR-setup, dynamic optimization calculations under the restrictions of the constructed reactor setup, were performed to determine the operation parameters. Furthermore, the experiment was designed to be comparable to already published results of a miniplant operation with a single CSTR. The comparison of the results with the assumptions of Kaiser et al. [13] revealed, that the assumptions were correct. Due to the specification of the intermittent flow regime and the coiling of the tube, high gas-liquid mass transfer ratios, less axial backmixing and very good liquid mixing properties, were achieved. Computational fluid dynamic calculations showed that the geometrical parameters have minor impact on the mixing efficiency in a

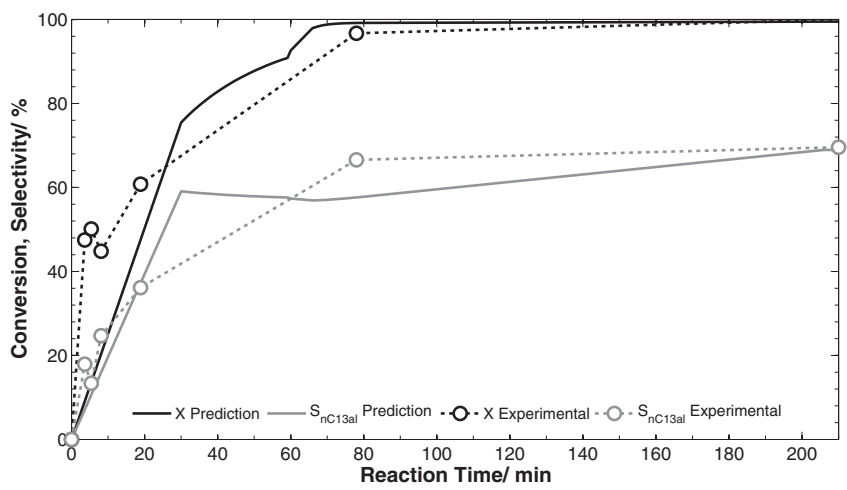

Fig. 14. Comparison of the conversion $\mathrm{X}$ and tridecanal selectivity $\mathrm{S}_{\mathrm{nCl3al}}$ between the model prediction and miniplant experiment.

medium range of the Reynolds-number, what supports the choice of a big coil diameter of the experimental setup. During the miniplant experiment a tridecanal selectivity of 0.70 and full conversion were achieved. The results are in excellent agreement to the predictions of the dynamic optimization calculations. Compared to literature results, the tridecanal yield and 1-dodecene conversion could be enhanced by $9 \%$ and $25 \%$, respectively.

Summed up, the results of the presend work confirm the assumptions made by Kaiser et al. [13] and validate the tandem reactor design determined by the usage of the flux profile analysis.

Currently, the integration of a process infrared spectrometer into the miniplant setup is in progress, for the elimination of the errors caused by manual sampling. However, due to the high molar solvent amount, the usage of advanced chemometric methods will be necessary to develop a robust analysis method. As the HCTR + CSTR-tandem is ideal for two-pot tandem reactions, it is planed to perform hydroaminomethylation-reactions of long chain olefins.

\section{Acknowledgment}

This work is part of the Collaborative Research Center/Transregio 63 "Integrated Chemical Processes in Liquid Multiphase Systems" (subproject B1). Financial support by the Deutsche Forschungsgemeinschaft (DFG, German Research Foundation) is gratefully acknowledged (TRR 63). Furthermore, the author M. Jokiel likes to thank Claudia Bednarz, Holger Eisenschmidt, Markus Ikert, Steffen Linke, Karsten H.G. Rätze, Patrick Siegmund and Bianka Stein for their 
support during the operation of the miniplant, Steffen Linke for the rhodium leaching measurements and Dr. Liane Hilfert (Institute of Chemistry, Otto-von-Guericke University Magdeburg) for the 31P NMRanalysis.

\section{Appendix A. Supplementary data}

Supplementary data associated with this article can be found, in the online version, at https://doi.org/10.1016/j.cej.2018.09.221.

\section{References}

[1] A. Behr, Angewandte Homogene Katalyse, Wiley-VCH Verlag GmbH \& Co, KGaA Weinheim, 2008.

[2] A. Behr, C. Fängewisch, Temperature-dependent multicomponent solvent systems an alternative concept for recycling homogeneous catalyts, Chem Eng Technol 25 (2002) 143-147, https://doi.org/10.1002/1521-4125(200202)25:2<143::AIDCEAT143 > 3.0.CO;2-O.

[3] A. Behr, A.J. Vorholt, Homogeneous catalysis with Renewables, Springer nternational Publishing AG Switzerland, 2017.

[4] A. Börner, R. Franke, Hydroformylation: fundamentals, processes, and applications in organic synthesis, Wiley-VCH Verlag GmbH \& Co, KGaA Weinheim, 2016.

[5] Y. Brunsch, A. Behr, Temperature-controlled catalyst recycling in homogeneous transition-metal catalysis: minimization of catalyst leaching, Angewandte Chemie Int Ed 52 (2013) 1586-1589, https://doi.org/10.1002/anie.201208667.

[6] J. Dreimann, P. Lutze, M. Zagajewski, A. Behr, A. Górak, Highly integrated reactorseparator systems for the recycling of homogeneous catalysts, Chem Eng Process 99 (2016) 124-131, https://doi.org/10.1016/j.cep.2015.07.019.

[7] J.M. Dreimann, H. Warmeling, J.N. Weimann, K. Künemann, A. Behr, A.J. Vorholt, Increasing selectivity of the hydroformylation in a miniplant: catalyst, solvent and olefin recycle in two loops, AlChE J 62 (2016) 4377-4383, https://doi.org/10. 1002/aic.15345.

[8] M. Gerlach, D. Abdul Wajid, L. Hilfert, F.T. Edelmann, A. Seidel-Morgenstern, C. Hamel, Impact of minor amounts of hydroperoxides on rhodium-catalyzed hydroformylation of long-chain olefins, Catal Sci Technol 7 (2017) 1465-1469, https://doi.org/10.1039/C7CY00244K.

[9] R. Gruber, T. Melin, Radial mass-transfer enhancement in bubble-train flow, Int J Heat Mass Transfer 46 (2003) 2799-2808, https://doi.org/10.1016/S0017 9310(03)00053-X.

[10] B. Hentschel, A. Peschel, H. Freund, K. Sundmacher, Simultaneous design of the optimal reaction and process concept for multiphase systems, Chem Eng Sci 115 (2014) 69-87, https://doi.org/10.1016/j.ces.2013.09.046.

[11] B. Hentschel, G. Kiedorf, M. Gerlach, C. Hamel, A. Seidel-Morgenstern, H. Freund, K. Sundmacher, Model-based identification and experimental validation of the optimal reaction route for the hydroformylation of 1-dodecene, Ind Eng Chem Res 54 (2015) 1755-1765, https://doi.org/10.1021/ie504388t.

[12] M. Jokiel, L.-M. Wagner, M. Mansour, N.M. Kaiser, K. Zähringer, G. Janiga, K.D.P. Nigam, D. Thévenin, K. Sundmacher, Measurement and simulation of mass transfer and backmixing behavior in a gas-liquid helically coiled tubular reactor,
Chem Eng Sci 170 (2017) 410-421, https://doi.org/10.1016/j.ces.2017.01.027 [ISSN 0009-2509].

[13] N.M. Kaiser, M. Jokiel, K. McBride, R.J. Flassig, K. Sundmacher, Optimal reactor design via flux profile analysis for an integrated hydroformylation process, Ind Eng Chem Res 56 (2017) 11507-11518, https://doi.org/10.1021/acs.iecr.7b01939.

[14] N.M. Kaiser, R.J. Flassig, K. Sundmacher, Reactor network synthesis via flux profile analysis, Chem Eng J 1018-1030 (2018) 335, https://doi.org/10.1016/j.cej.2017. 09.051.

[15] G. Kiedorf, D.M. Hoang, A. Müller, A. Jörke, J. Markert, H. Arellano-Gracia, A. Seidel-Morgenstern, C. Hamel, Kinetics of 1-dodecene hydroformylation in a thermomorphic solvent system using a rhodium-biphephos catalyst, Chem Eng Sci 115 (2014) 31-48, https://doi.org/10.1016/j.ces.2013.06.027.

[16] Kováts P, Thévenin D, Zähringer K. Optical measurement of oxygen mass transfer in a coiled reactor, 2017. ProcessNet Jahrestagung 14.-17.3. Dresden, paper 7032, page 7044 .

[17] Kováts P, Martins F, Thévenin D, Zähringer K. Tomographic PIV measurements in a helically coiled reactor, 4.-7. September 2018a. In: Vad J. (Ed.), Conference on Modelling Fluid Flow (CMFF'18): The 17th International Conference on Fluid Flow Technologies Budapest, Hungary, No. CMFF18-054, ISBN 978-963313297-5.

[18] P. Kováts, D. Pohl, D. Thévenin, K. Zähringer, Optical determination of oxygen mass transfer in a helically-coiled pipe compared to a straight horizontal tube, Chem Eng Sci 190 (2018) 273-285, https://doi.org/10.1016/j.ces.2018.06.029.

[19] M. Mansour, Z. Liu, G. Janiga, K.D.P. Nigam, K. Sundmacher, D. Thévenin, K. Zähringer, Numerical study of liquid-liquid mixing in helical pipes, Chem Eng Sci 172 (2017) 250-261, https://doi.org/10.1016/j.ces.2017.06.015.

[20] M. Mansour, G. Janiga, K.D.P. Nigam, D. Thévenin, K. Zähringer, Numerical study of heat transfer and thermal homogenization in a helical reactor, Chem Eng Sci 177 (2018) 369-379, https://doi.org/10.1016/j.ces.2017.11.031.

[21] M. Mansour, P. Khot, D. Thévenin, K.D.P. Nigam, K. Zähringer, Optimal reynolds number for liquid-liquid mixing in helical pipes, Chem Eng Sci (2018), https://doi. org/10.1016/j.ces.2018.09.046.

[22] J. Markert, Y. Brunsch, T. Munkelt, G. Kiedorf, A. Behr, C. Hamel, A. SeidelMorgenstern, Analysis of the reaction network for the rh-catalyzed hyroformylation of 1-dodecene in a thermomorphic multicomponent solvent system, Appl Catal A: General 462-463 (2013) 287-295, https://doi.org/10.1016/j.apcata.2013.04.005.

[23] H. Pedersen, C. Horvath, Axial dispersion in a segmented gas-liquid flow, Ind Eng Chem Fundam 20 (3) (1981) 181-186, https://doi.org/10.1021/i100003a001 [ISSN 0196-4313].

[24] E. Schäfer, Y. Brunsch, G. Sadowski, A. Behr, Hydroformylation of 1-dodecene in the thermomorphic solvent system dimethylformamide/decane. phase behavior reaction performance - catalyst recycling, Ind Eng Chem Res 51 (2012) 10296-10306, https://doi.org/10.1021/ie300484q.

[25] VDI-Gesellschaft, VDI-Wärmeatlas, Springer Verlag Berlin Heidelberg, 2010 [10 edition].

[26] M. Zagajewski, A. Behr, P. Sasse, J. Wittmann, Continiously operated miniplant for the rhodium catalyzed hydroformylation of 1-dodecene in a thermomorphic multicomponent solvent system (tms), Chem Eng Sci 115 (2014) 88-94, https://doi. org/10.1016/j.ces.2013.09.033.

[27] M. Zagajewski, J. Dreimann, A. Behr, Verfahrensentwicklung vom Labor zur Miniplant: Hydroformylierung von 1-Dodecen in termomorphen Lösungsmittelsystemen, Chemie Ingenieur Technik 86 (2014) 449-457, https://doi. org/10.1002/cite.201300147. 